\title{
Erratum zu: Festigkeitsberechnung
}

\author{
Erratum zu: \\ Kapitel 3 in: \\ Herbert Wittel et al., Roloff/Matek Maschinenelemente \\ https://doi.org/10.1007/978-3-658-26280-8_27
}

Während der Korrekturphase wurde in Tabelle TB 3-1 a) Dauerfestigkeitsschaubilder in Teilbild a) eine korrigierte Teilabbildung eingesetzt, was eigentlich in TB 3-1 c) hätte erfolgen müssen. Es wurde deshalb jeweils Teilbild a) in TB 3-1 a) und c) durch die korrekte Version ersetzt.

TB 3-1 Dauerfestigkeitsschaubilder

a) Dauerfestigkeitsschaubilder der Baustähle nach DIN EN 10025; Werte gerechnet, s. TB 1-1

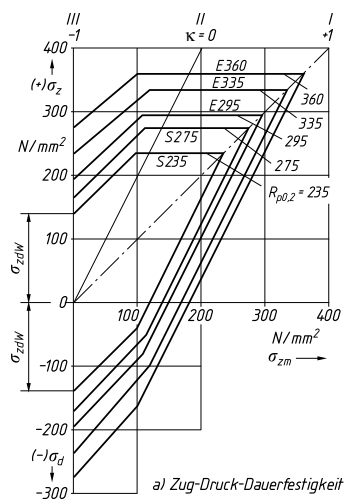

TB 3-1 (Fortsetzung)

c) Dauerfestigkeitsschaubilder der Einsatzstähle nach DIN EN 10084;

(im blindgehärteten Zustand; Werte gerechnet, s. TB 1-1)

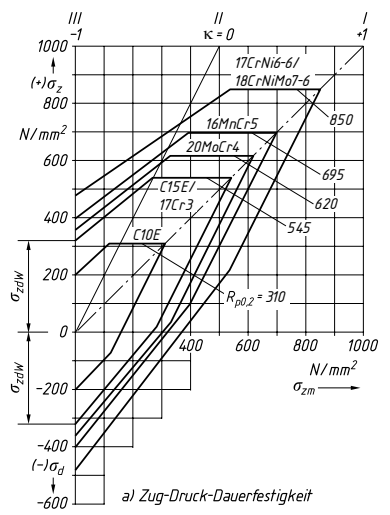

Die aktualisierte Version des Kapitels kann hier abgerufen werden: https://doi.org/10.1007/978-3-658-26280-8_27 